\title{
Space Industry Development: Opportunities and Challenging in Thailand
}

\author{
Jesada Sivaraks $^{\# 1}$, Settapong Malisuwan ${ }^{\# 2}$, Wassana Kaewphanuekrungsi ${ }^{\# 3}$ \\ ${ }^{\# 1}$ Head of Government \& Industry Relations, Ericsson Thailand, \\ ${ }^{2}$ Member of the House of Representatives, Vice-Chairman of Communications, Telecommunications, and the \\ Digital Economy and Society Committee, \\ ${ }^{3}$ Specialist to Member of the House of Representatives
}

\begin{abstract}
Satellites are technology developed to be able to orbit in space utilizing Earth's gravity. Therefore, Satellite technologies are suitable for long-distance communications and are used for various activities in many fields such as telecommunications, geological surveys, the military, research, agricultural planning, maps and urban planning, etc. Satellite technology is one of the most important technologies for the stability as well as advancement of the telecommunication infrastructure of a country. Technological advancement has caused satellite businesses to evolve rapidly as well as create a variety of new business opportunities.
\end{abstract}

Nowadays, the space industry has become a point of interest for many sectors. In terms of communication, this has allowed us to access the internet in areas where it previously didn't exist. There are many studies which discuss the barriers to connectivity across the world. One reason for this lies in a lack of economic viability when it comes to providing internet services in the support of terrestrial infrastructure. A possible solution to this problem is the development of air and space internet access using balloons, drones, or even satellites. However, many wonder what possible challenges would arise along with the possible legal limitations. Suffice it to say, there might be multiple technical and even operational limitations such as the possibility of property damage or even problems related to orbit. According to studies from various research institutes around the world the consensus is that the possibility of internet access all over the world would indeed greatly benefit humanity as well as bring various economic and social benefits.

In this paper, we will discuss the current state of things. We will also discuss the future of space industries around the world including in Thailand. We will then study the possibility of providing space-based internet services and the various aspects of that possibility. We will take a look at expert interviews, literature reviews, as well as study various articles from both domestic and international space and technology ventures that experienced development issues.

Keywords —Challenge, Opportunity, Space Economy, Space Industry, Thailand

\section{INTRODUCTION}

Space technology has a long history. As well, it has been through continuous evolution. But over the past decade, it has changed rapidly. In many different fields, governments and government agencies have worked tirelessly to drive research as well as aerospace services. However, in the near future, space technology will cause significant changes and will drive a revolution to commercial services. It will also cause change in human spaceflight production as well as space operations. In modern society we are more dependent than ever on space technology. Things like telecommunications, broadcasting, environment checks, and weather forecasts all rely on satellites to some extent.

Entrepreneurs in the space industry are now achieving more of their goals than ever before. For example, they can now easily obtain government support for various projects. They have also been able to reduce costs and the time required by the government when it comes to developing various space systems. The government in many countries support space industry by using economic tools and set up supportive economic policies. This then would help support the domestic space industry as well as achieve international goals. Things like funding, research and development subsidies, access to government facilities and technology subsidies, and the launch of new services and testing platforms would all be welcome improvements. However, all this should be directed through organizations which are designed to facilitate space technology research and development. 
DOI: $\underline{10.51386 / 25815946 / \mathrm{ijsms}-\mathrm{v} 4 \mathrm{i} 5 \mathrm{p} 106}$

Volume: 4 Issue: $5 \quad$ September to October $2021 \quad$ https://www.ijsmsjournal.org

\section{SPACE ECONOMY}

The global space economy was worth $\$ 415$ billion in 2019 [1], this included various industries such as entertainment satellites, communications, and real-time services. Other examples include navigation and weather forecasts. It has been found that since 2009 there has been an increase in commercial investment in the space industry. The introduction of Elon Musk's commercial space firm Space X has disrupted the industry greatly. Morgan Stanley's Space Team estimates that global space industry could be worth over $\$ 1$ trillion by 2040. According to estimates by Goldman Sachs and Bank of America the space economy will be worth over $\$ 1.5$ trillion in 20 years from now [2].

The space economy is changing fast. For decades, new civilian uses of space have been emerging at a rapid pace. General communications in the 1960s, TV broadcasts in the 1970s, and navigation in the 1980s. In contrast to this, new uses for space is now emerging all at once [3]. Companies are now able to make a profit in areas like [4]: earth observation, global high-speed internet, tourism, debris removal, research, manufacturing, construction, resource extraction, and, possibly, in settlement, threat mitigation, and security. In parallel with this, new regulatory regimes are being formed along with the development of legal frameworks for use in space.

\section{III.UTILIZATION OF SATELLITES}

The private sector has shown considerable interest in investment in the space industry in recent years. Interestingly, this has caused the public sector to become more involved as well. In August 2018, NASA announced a team of astronauts was to depart for International Space Station (ISS) via a commercially developed rocket in the United States. Which this development greatly benefited the US Department of Defense as well as the aerospace industry as a whole. This will also help to promote and accelerate investment in space technology.

In the near future, the space industry is likely to affect many industries in huge ways. Examples of which include aerospace and defense industries. Specifically, within these, the industries that are most likely to be affected include the IT industry as well hardware and telecommunication. Morgan Stanley estimates that the world's space industry will generate more than $\$ 1$ trillion in revenue by 2040 , up from the $\$ 350$ billion today. The most important short- and medium-term opportunities will appear in the world of high-speed internet connection via satellite [5].

\section{IV.GLOBAL SATELLITE INDUSTRY}

In the past, satellite services focused on fixed orbiting satellites (Geostationary Satellite Orbit : GSO) but the current trend has shifted towards investing in service businesses for things like non-stationary orbital satellites (Non-Geostationary Satellite Orbit: NGSO) such as Low Earth Orbit (LEO) satellites. Also, reusable rockets have been developed that enable them to create more satellites than ever before. Satellite technology is being applied in new digital industries. Currently, there are various uses for LEO satellites, high speed internet transmission or for the transmission of large amounts of data. There has also been further use of satellites to transmit television signals utilizing image technology, observation, navigation and high-quality cameras of all kinds. However, in 2019, global satellite industry generated around \$279 billion in revenue[6].

LEO is a satellite that orbits at an altitude of 350 to 2,000 kilometers from the Earth. It has become the true satellite of the digital disruption era, with leading global technology companies competing to develop LEO satellites for use in space. As well, many are attempting to develop satellite businesses. Examples of which include:

1) SpaceX's Starlink project.

2) Amazon's Project.

3) Facebook, Google and Apple planning.

\section{SATEllite INDUSTRY IN ThaIland}

Satellites in use in Thailand are operated by Thaicom Company Limited, which is the supervisory authority in the contract system. Concessions have been made with the Ministry of Digital Economy and Society (DES), paying a $22.5 \%$ annual revenue share to the government, providing all of 4 satellites. They are as follows:

- Thaicom4 (IPSTAR)

- Thaicom6 / Africom1

- Thaicom7 
DOI: $\underline{10.51386 / 25815946 / \mathrm{ijsms}-\mathrm{v} 4 \mathrm{i} 5 \mathrm{p} 106}$

\section{- Thaicom 8}

However, Currently Thaicom4, Thaicom6, Thaicom7, Thaicom8 satellites are still the property of Thaicom. But after the end of the concession, in September 2021, Thaicom4 satellites are set to become the property of DES, but the age of satellites in Thailand is far from over. For example, Thaicom4 which expires in 2023, at the end of its life it will be fired out of orbit as space junk. But when the concession contract with Thaicom expires, it will be up to DES to carry on the mantle. Liberalization of new satellites under the control of NBTC will allow new satellites to be created in the future.

The current trend of small satellite development has also accelerated Thailand's satellite industry. An example of said acceleration exists in companies like CAT Telecom Public Company Limited. CAT has negotiated a partnership by proposing the use of CAT ground satellite space to support over 800 LEO satellites. Another example of which includes the KNACKSAT team of King Mongkut's University of Technology North Bangkok, where satellites are manufactured within Thailand and can be successfully sent into orbit at an altitude of 600 kilometers.

Therefore, the technological transformation of the $21^{\text {st }}$ century have not at all been the same as in the last century. Exponential Technology is not only highly potent in itself, but if it is applied properly, it will become the most powerful technology to have ever existed.

\section{VI.TRANSFORMATION OF THE SPACE INDUSTRY}

The global space market has evolved and grown markedly over the past decade. It is estimated that the space industry will be worth about $\$ 176$ billion in 2006 and has expanded by more than $\$ 345$ billion in 2018, with private equity investment growing over the past two decades, with the estimate that from 2000 to 2014, space startups received investments in joint ventures of $\$ 1.1$ billion, or about $\$ 73$ million per year, in 2015 . More than $\$ 1.8$ billion investments in 2016, more than 100 investors contributed $\$ 2.8$ billion to 43 space startups, an average investment of $\$ 57.1$ million, while in 2017 more than 120 investors gave $\$ 3.9$ billion to commercial space companies, adding nearly $40 \%$ to investment within a year.

\section{A. New Space}

In the past, the space ecosystem was controlled by national governments, but over the years we have seen significant changes in space affairs around the world. to greater participation of the private sector. These changes are under the concept of "New Space", which has attracted a lot of attention from many. This concept is relevant to technological innovation.

Understanding the sub-lining of changes in the space ecosystem is important, which can be both an opportunity and a challenge, and New Space could be a new investor, or it could be the same investor who is trying to create and collaborate with new investor to innovate new models to transform the industry.

One of the features of new space is that private firms are no longer simply operating as contractors to nation states but are themselves becoming key protagonists in space. To take one notable example, in 2018, Space X launched 15 rockets, which among other things sent a Luxembourg-made satellite to be used by NATO into orbit [7]. It also sent a Tesla automobile into space as a marketing stunt and a way to announce that the company was prepared to reinvent the way companies conceive of space, and European firms now rival their American competitors across an array of technologies. At the same time, developing countries are making significant advances in their own their space programs. China may now be spending more on space than the Russian Federation [8].

Traditionally, investors have considered the commercial opportunities of space to be "high risk, high cost, and long payment periods [9]. Several important changes, however, have dramatically reduced barriers to entry and increased private interest in space. For example, Space X has expressly designed its Falcon rockets, to maximize standardization, which, in turn, has reduced the number of processes and the tooling required prior to any given launch while diminishing unit costs of critical parts. The digital revolution and monetarization have increased the power of critical satellite technology while reducing its size and weight - key drivers of launch costs. 
DOI: $\underline{10.51386 / 25815946 / \mathrm{ijsms}-\mathrm{v} 4 \mathrm{i} 5 \mathrm{p} 106}$
Volume: 4 Issue: 5
September to October 2021
https://www.ijsmsjournal.org

\section{B. Reusable rockets}

Reusable rockets are among the most promising of these advances provided the restoration costs, which are currently very high, are under control. This technology substantially reduces costs by allowing officials to launch the same rocket multiple times. In 2015, Blue Origin, designed and launched a reusable suborbital rocket, which will help that company substantially reduce its production costs [10].

The transition to a sharing economy in space is one of the social transformations that has shifted from large entrepreneurs at the government level and large enterprises to small startups, not only to deploy new technologies to support traditional applications. But there are also more and more new applications being developed.

\section{Traditionally government support}

Traditionally government support has been a critical driver of technological change linked to the space industry. Private corporations in the United States, for example, were long granted access to their country's space agency's technical archive. They also benefited from the secondment of NASA experts [11]. Cooperation between government scientists and private industry triggered compelling advances in an array of critical components, such as heat shield materials, that ultimately also had important commercial applications [12]. Governments have also played a compelling financial role and sustaining the space sector through a system of research grants, contracts, and other agreements with the private sector. The United Launch Alliance, a joint program between Boeing and Lockheed Martin, for example, receives roughly $\$ 800$ million a year from the US military through a launch capability contract [13].

\section{The government support investment policies}

By 2025, there will be investment in next-generation communication satellites, which require advanced twoway communication solutions to maximize network efficiency so that more than 10,000 satellites can be connected to more than 15 million remote areas around the world. Moreover, the Global Datasphere where digital content is created, will grow to $175 \mathrm{ZB}$ yearly by 2025 [14]. These two market changes will create significant new opportunities and a growing need for a holistic approach. As for how to design and build new solutions for the space industry, satellite trends are smaller and take less time to build and spend less money on building than in the past. Since 2014, hundreds of small satellites have been launched. It is estimated that the number of small satellites to launch between 2018 and 2027 will be 6,500 - 7,000.

In addition to the government's driving, the investment of big companies like Space X, Virgin Galactic and Blue Origin and a lot of venture capitalists had led to changes in the space industry. Cumulatively, $\$ 25.7 \mathrm{~B}$ has now been invested into 535 unique space companies since 2009-2019 [15].

New policies have encouraged competition and helped open the commercial market to other actors. This competition has, in turn, created incentives for the industry to build ever cheaper and more capable products. In 2006, NASA stopped using government-operated rockets to resupply the International Space Station and has since relied on private industry [16].

Difference services cost in each company represents a profoundly disruptive change to the industry with long-term commercial, scientific and even military-security implications. [17] The price fall is a function of regulatory change, managerial innovation, competition and critical technical innovation.

These advances have also sparked intense interest among well-financed space enthusiasts and entrepreneurs. Motivated by an abiding personal interest in space and driven by a belief that he could dramatically drive down costs, Elon Musk, the US entrepreneur who earned millions after selling his firm PayPal, founded Space X with a $\$ 100$ million investment primarily composed of his own money[18].Jeff Bezos, the founder of Amazon, is selling \$1 billion of stock a year to finance his aerospace company, Blue Origin[19]. These entrepreneurs have a personal interest in space and a belief that they can push out the space frontier while identifying projects that can generate long-term profits. Their personal wealth has afforded them the opportunity to stretch out investment horizons in this changing but still high-cost and risky business. 
DOI: $\underline{10.51386 / 25815946 / \mathrm{ijsms}-\mathrm{v} 4 \mathrm{i} 5 \mathrm{p} 106}$
Volume: 4 Issue: 5
September to October 2021
https://www.ijsmsjournal.org

\section{OPPORTUNITIES AND CHALLENGES}

Development Opportunities for the Satellite Industry in Thailand as well as possible challenges.

\section{A. Technologies that are relevant Thailand's needs}

Based on the above-mentioned space technology trends, it can be seen that communications satellites are developed to respond needs of high-speed data communication. It is capable of covering areas all over the world. This can cover more areas on Earth than ground networks. It can be concluded that communications satellite technology can meet the following requirements

1. High throughput satellite (HTS) is High-speed transmission support which increases bandwidth capacity through adjusting frequency reuse. The size of the beam depends on the size of the antenna at the satellite station and the frequency used.

2. Adjusting the active band to a higher frequency band increases bandwidth, such as Ku-band, Ka-Band, or $\mathrm{mm}-$ Wave, that suitable for increasing capacity and reducing the antenna size.

3. The satellite's orbital level affects the coverage area and latency duration. High-capacity communications satellites are available in geo and NGEO orbits, depending on the purpose and type of use. A geosynchronous orbit is a High-capacity regional data communication services that allows satellites to match Earth's rotation. Located at 35,786 kilometers. Which is very far from earth, causing high latency.

4. The MEO or LEO orbital satellite service consists of a large number of small satellites connected to the network to increase the coverage of the space. As a result, this type of satellite has low latency (less than 5 milliseconds), thus making the satellite network low in orbit. It is compatible with terrestrial communication networks such as, 5G Technology.

\section{B. Opportunities for the Satellite Industry Development in Thailand}

In the future, there will be a large number of satellites for providing internet access. And the world is trending toward many services based on non-fixed satellites. Examples of such satellites include NGSO, LEO and MEO satellites. These satellites are smaller and can also be sent into orbit at the same time. These satellites provide a variety of services such as high-speed internet, high speed transmission, and TV connection signals. They offer higher quality image technology as well as other services including general exploration, navigation, maps, and high-quality images of all kinds.

Technological developments have enabled NGSO satellites to provide low latency internet and data services. This has significantly shortened transmission times as well. So, NGSO satellites become a new business tool that require the high-speed internet transmission at all times. There are many more uses for these satellites including support for unmanned aerial vehicles (UAV). They also help to provide high speed internet service to remote areas which might have previously not have had access to the internet. These drones also help to facilitate sea and desert and exploration of all kinds [20].

\section{Challenges in Thailand}

As many are aware, Thailand started the satellite liberalization project. In the past, the only company invested in this sector was Thaicom Public Company Limited which was the only communication satellites operating satellite business in Thailand. As of 2021, Thaicom4, Thaicom5 and Thaicom6 will end the concession and all assets must then be returned to the government and the Council of Ministers. Approval will then be sought for further action related to stationary orbit satellite business. In order to comply with Article 60 of the Constitution of the Kingdom of Thailand there are certain rights given to foreign satellites when it comes to transmitting and receiving signals (Landing Rights) in Thailand. This topic must be looked at urgently as to the details and conditions for the liberalization as well landing rights for foreign satellites. The goal of this will be to allow then enter the satellite business in Thailand. But of course, this is considered a matter at the national policy.

The Ministry of Digital Economy and Society (DES) is to act in governance while the television business and the National Telecommunications Commission (NBTC) must be responsible for obtaining a license and landing. 
DOI: $\underline{10.51386 / 25815946 / \mathrm{ijsms}-\mathrm{v} 4 \mathrm{i} 5 \mathrm{p} 106}$

Volume: 4 Issue: 5
September to October 2021

\author{
https://www.ijsmsjournal.org
}

According to an act on the organization of allocation frequency and regulation radio broadcasting, NBTC's new version is pending announcement in the government gazette. In Thailand after the new law has come into effect, it will be necessary to clearly separate the authority of the DES and NBTC. This new law will create a license of operation. Under the authority NBTC, the Ministry of DES will be responsible for planning business policies. This will be done to support the liberalization of satellites in Thailand. This of course, must be supervised effectively and many plans and preparations must be made. There is also a strong need to determine the direction of the regulatory policy in terms of enabling satellite businesses to have more foreign operators visit.

As well, regulations drafted by Space Affairs has made progress when it comes to drafting the necessary laws. These drafts are about to be proposed to the counsel. Representatives are of the opinion that this draft law will play an important role in supporting the development of industries and businesses that are related to space affairs in Thailand. However, it is important to note that laws of this nature have never before been drafted or passed. There are many other things that have never before been tried including the registering of space objects, space accident management, and the allowance of satellite objects in space.

As well, discussion with central agencies will take place. These agencies will act as the governing body of space affairs. They will also act as a legislator and control many aspects of the project in a supervisory manner. In accordance with the regulations stipulated by law, the Office of Policy Affairs will also be established.

The National Space Policy Committee acknowledges the progress of the strategic advocacy of space affairs because the rapid development of space technology. This can be seen best when one takes a look at the National 20-Year Master Plan (2017-2036). However, it is also important to note that there is a large quantity of satellites, and space objects including space junk orbiting the Earth. This could then be detrimental to the operation of satellites for many countries around the world including Thailand. Thailand currently has quite a few satellites in space. Including communication satellites, resource satellites and specialized satellites which are the property of governmental and educational institutions. This makes Thailand more likely to be affected by these other satellites.

Therefore, a subcommittee should be formed with the goal of formulating surveillance policies and plans when it comes to space traffic. The Ministry of Defense plays the largest role in international relations and security. However, all related agencies in all sectors should be encouraged to jointly support each other and work together.

The National Space Policy Committee should control, monitor and drive implementation to achieve tangible results as quickly as possible. As well, the Ministry of Digitalization for Economy and Society should have the authority to define and drive the country's space affairs policies. This will be done to meet all goals in as a concrete way as possible. We must not forget that cooperation between all sectors and involved parties will drive the development of Thailand's space affairs forward.

\section{CONCLUSIONS AND RECOMMENDATIONS}

The Aerospace Industry in Thailand is one of the $10 \mathrm{~S}$-Curve or target industries that is continuously being promoted by the Eastern Economic Corridor EEC or by the industry in general. However, advanced technology is crucial for its operation. This corresponds to the strengths of target industries that the EEC wants to promote in the 3 Eastern provinces.

The growth of the aerospace industry in Thailand that has strong support from government policy makers as well as investment promotion measures from relevant government agencies. It is important to continually be aware of the competition capacity of enterprises in the industrial sector of Thailand and on a global scale. This will affect the expansion of the domestic economy in the long run, as well as build a stronger Thai aerospace industry. In total, there are currently only 26 operators in Thailand who have passed the Aerospace Standard AS9100 industry standard. While in Singapore, up to 119 agencies meet this standard. In Malaysia, there are currently 60 agencies who meet this standard. This indicates that Thai aerospace and aviation entrepreneurs must continually work toward creating the future of space industry that we so much want to be realized. Both in terms of standards and enhancing the potential of production technology. To compete on a global stage, the development of the aerospace industry, technology, and innovation should be the primary focus of policy 


\section{DOI: $\underline{10.51386 / 25815946 / i j s m s-v 4 i 5 p 106}$}

Volume: 4 Issue: 5
September to October 2021 https://www.ijsmsjournal.org

makers. This includes the continued utilization of the aerospace technology as well as the development of technology infrastructure in the aerospace industry which will help to develop the new S-Curve.

It is important to note that many countries have formed treaties and conventions when it comes to the laws of space. Thailand is currently a member of one such treaty. The treaty being of the Space and Landscape Technology Development Agency. It is updating its draft for the Space Affairs Act. As well, Thailand is currently gathering opinions from experts from various departments. The amendment of said Act seeks to achieve two main things: the creation of the National Space Policy Committee. Which will play a role in formulating corporate policy and the establishment of the Space and the National Space Regulatory Office. It is important that the government consider establishing a space fund. This will allow for continued support for Space Affairs and will also promote the continued development of the new S-Curve industry. This should be a priority in Thailand is order to allow for a stable economic future. It is important to note that this is the essence of the draft of the Space Affairs Act. There are a wide range of areas when it comes to space affairs that are not yet covered by specific laws. Being that this is a new industry on many levels, it can be clearly seen that many projects currently being attempted have never been attempted by any organization. This includes things like the registration of space objects, space accident management, and the creation of satellites and space objects. Things like this are typically looked after by specific organizations with specific abilities to look after things like spectrum, orbits, landing rights, and equipment.

Therefore, it is paramount that Thailand create Space Agency to act as the main agency in space affairs, both domestically and aboard. This space agency will be responsible for the security and safety of all space affairs. This then includes the creation of regulations in Thailand in matters relating to space affairs and space technology in accordance with international regulations. This Space Agency will also create a process for governing space affairs in Thailand and take care and protect the interests of other countries as well as our own.

If this draft of the Space Affairs Act is considered by the ministry and then forwarded to the council for consideration, we think we will all find that this will benefit our country greatly. We mustn't forget that at present, many countries are rapidly developing their space industry sector. We must continue to fight for the delivery of spacecraft, satellites, as well as the creation of business that relate to space. When it comes to the space industry in Thailand, we have a couple of options. We could either send satellites up ourselves or we could work closely with NASA. Either or both of these options will allow Thailand to keep up with other countries when it comes to space industry. Therefore, this law should be accelerated and approved as quickly as possible.

\section{REFERENCES}

[1] Space Foundation, “The Space Report 2020,” 2020.

[2] Satellite Industry Association, Morgan Stanley Research, "A New Space Economy on the Edge of Liftoff," 2019.

[3] Space Foundation, The Space Report: The Authoritative Guide to Global Space Activity,” 2019.

[4] Elvis M, (2020), "Space Economy Grand Challenges". Front. Space Technol. 1:4. doi: 10.3389/frspt.2020.00004

[5] Morgan Stanley, "Does Earth’s Future Depend on Space," 2019.

[6] Statista, "Space Industry worldwidw," 2020.

[7] SpaceX, "Updates: Launch Manifest," 5 Sep 2018, https://www.spacex.com/missions

[8] Clark, Stuart, “China: the new space superpower”, The Guardian, 28 August 2016.

[9] Wakimoto, Takuya, "How to reduce US space expenses through competitive and cooperative approaches", The Space Review, 22 Jan 2018, http://www.thespacereview.com/article/3412/1

[10] Kim, Gene and Jessica Orwig, "Here's a first look at Jeff Bezos' monster rocket factory”, Business Insider UK, 2017, http://uk.businessinsider.com/jeff-bezos-space-company-blueorigin-new-rocket-factory-florida-2017-8?r=US\&IR=T

[11] Chaikin, Andrew, "Is SpaceX Changing the Rocket Equation?", Air \& Space, Jan 2012, https://www.airspacemag.com/space/isspacex-changing-the-rocket-equation132285884/?all

[12] Werner, Debra, "SpaceX Leaves Searing Impression on NASA Heat Shield Guy”, SpaceNews, March 2015. 
DOI: $\underline{10.51386 / 25815946 / \mathrm{ijsms}-\mathrm{v} 4 \mathrm{i} 5 \mathrm{p} 106}$

Volume: 4 Issue: 5

[13] Gruss, Mike, “U.S. Air Force evaluating early end for ULA’s \$800 million in yearly support”, SpaceNews, 27 Jan 2016.

[14] IDC, "Data Age 2025 : The Digitization of the World," 2018.

[15] Space Angels, "Space Investment Quarterly Q4 2019," 2020.

[16] Grush, Loren, "NASA is saving big bucks by partnering with commercial companies like SpaceX", The Verge, 10 Nov, 2017.

[17] Routh, Adam, “Why America’s Space Launch Must be Competitive”, National Interest, Jan 2017.

[18] Tilley, Aaron, "Seat Of Power: Tesla And SpaceX Investor Steve Jurvetson”, Forbes, 2016.

[19] St. Fleur, Nicholas, "Jeff Bezos Says he Is Selling \$1 Billion a Year in Amazon Stock to Finance Race to Space”, New York Times, 2017.

[20] NIDA, "Report on the Study of Economic and Social Value in the Space Industry in Thailand," 2019. 